\title{
Posterior crossbite - treatment and stability
}

Renato Rodrigues de ALMEIDA', Marcio Rodrigues de ALMEIDA', Paula Vanessa Pedron OLTRAMARI-NAVARRO', Ana Cláudia de Castro Ferreira CONTI' ${ }^{1}$ Ricardo de Lima NAVARRO ${ }^{1}$, Henry Victor Alves MARQUES ${ }^{2}$

1- DDS, MSc, PhD Full Professor, Department of Orthodontics, University of North Paraná (UNOPAR), Londrina, PR, Brazil.

2- DDS, MSc student, Department of Orthodontics, University of North Paraná (UNOPAR), Londrina, PR, Brazil.

Corresponding address: Marcio Rodrigues de Almeida - Avenida José Vicente Aiello, 170 - Tivoli - 17053-093 - Bauru - SP - Phone: (14) 3226-1411 - e-mail: marcioralmeida@uol.com.br

Received: April 05, 2010 - Modification: May 20, 2010 - Accepted: May 20, 2010

\section{ABSTRACT}

\begin{abstract}
Dosterior crossbite is defined as an inadequate transversal relationship of maxillary and mandibular teeth. Even when eliminating the etiologic factors, this malocclusion does not have a spontaneous correction, and should be treated with maxillary expansion as early as possible. This treatment aims at providing a better tooth/skeletal relationship, thereby improving masticatory function, and establishing a symmetrical condyle/fossa relationship. Should posterior crossbite not be treated early, it may result in skeletal changes, demanding a more complex approach. Additionally, an overcorrection expansion protocol should be applied in order to improve the treatment stability. Although the literature has reported a high rate of relapse after maxillary expansion, the goal of this study was to demonstrate excellent stability of the posterior crossbite correction 21 years post treatment.
\end{abstract}

Key words: Orthodontics. Malocclusion. Palatal expansion technique.

\section{INTRODUCTION}

Posterior crossbite is defined as an inadequate transversal relationship of maxillary and mandibular teeth, i.e., the buccal cusps of the maxillary teeth are in contact with the central fossae of the mandibular teeth ${ }^{18,19}$. Some studies have suggested a posterior crossbite prevalence range between 8 to $16 \%{ }^{11,18-20}$. The etiology of this malocclusion may comprise deleterious oral habits and early loss of primary teeth, among others ${ }^{7,20}$. Regarding the problems that affect the maxillomandibular complex, the transversal arch stands out because of its limited growth, as the first dimension to stop growing ${ }^{16}$.

This malocclusion does not show spontaneous correction, and should be treated with maxillary expansion as early as possible $2,5,18-20$. Therefore, an accurate diagnosis and treatment planning must be accomplished with the patient in centric relation ${ }^{6}$. This approach should consider not only the tooth intercuspation, but also the arch shape, since constricted arches have a triangular anatomy ${ }^{2,5}$.

The early treatment aimed at promoting a better tooth/skeletal relationship, thus improving masticatory function, and establishing a symmetrical condyle/fossa relationship $p^{4,9,10,15,19}$. The treatment proposed for an early posterior crossbite correction comprises fixed or removable appliances, such as the Haas expander. This orthopedic appliance increases the transversal dimension of the maxillary dental arch by opening the median palatine suture, and due to proclinate maxillary posterior teeth ${ }^{18,19}$.

In order to achieve a better stability, an overcorrection of the maxillary expansion is suggested, since at least one third of relapse is expected ${ }^{1,18}$. Furthermore, aiming at minimizing this effect, removable or fixed retainers are indicated for at least 3 months ${ }^{1}$.

Although this treatment protocol has been extensively discussed in the literature, few studies on a long-term basis have been reported ${ }^{3,13,17}$. The aim of this study was to demonstrate the stability of the posterior crossbite correction 21 years after treatment.

\section{CASE REPORT}

A 12.8 year-old Caucasian girl presented for treatment complaining of an unpleasant smile. This patient showed oral breathing, lip incompetence, and atypical swallowing aided 


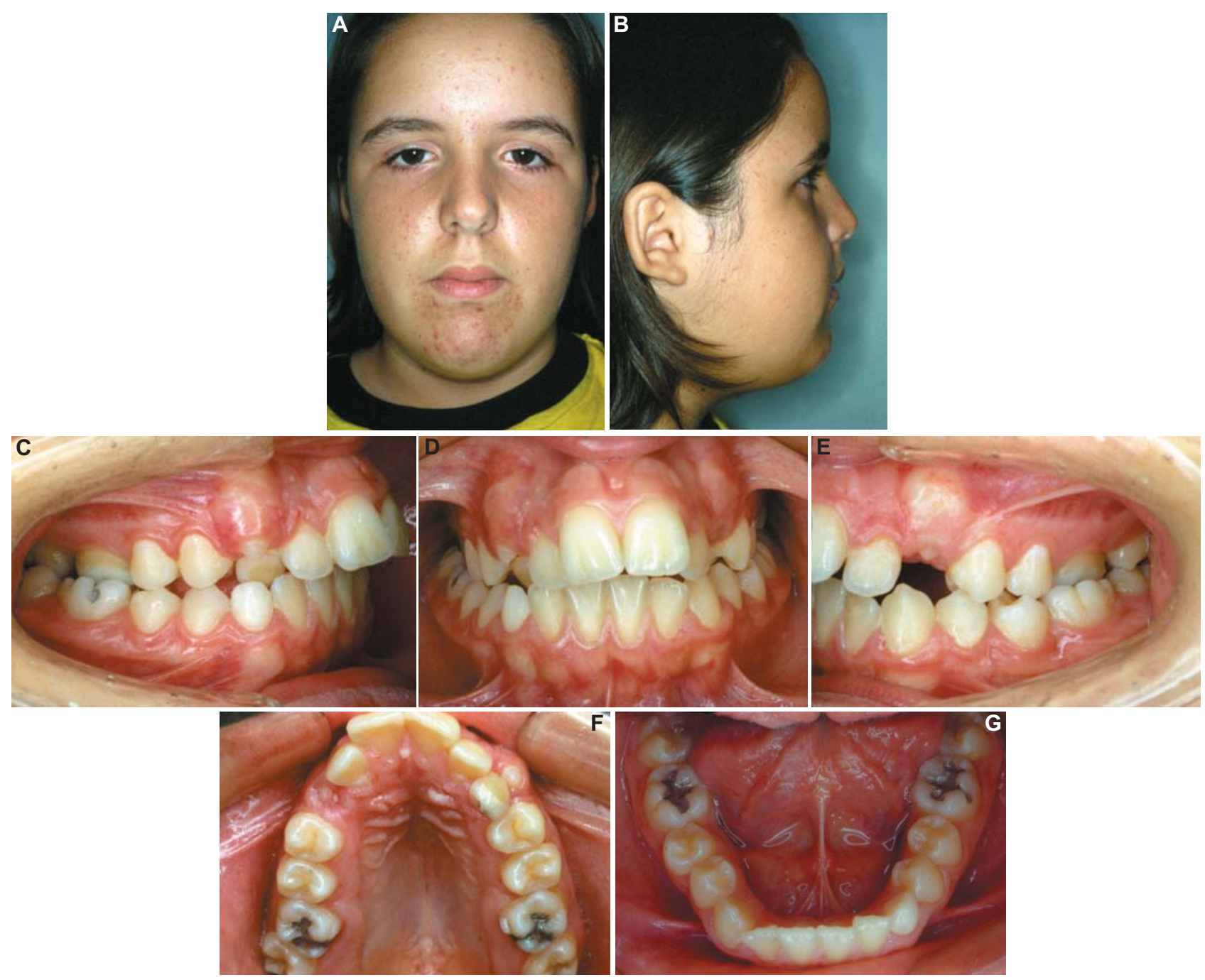

Figure 1- Pretreatment extraoral (A and $B$ ) and intraoral $(C-G)$ photographs (parents authorized the publication of these pictures)
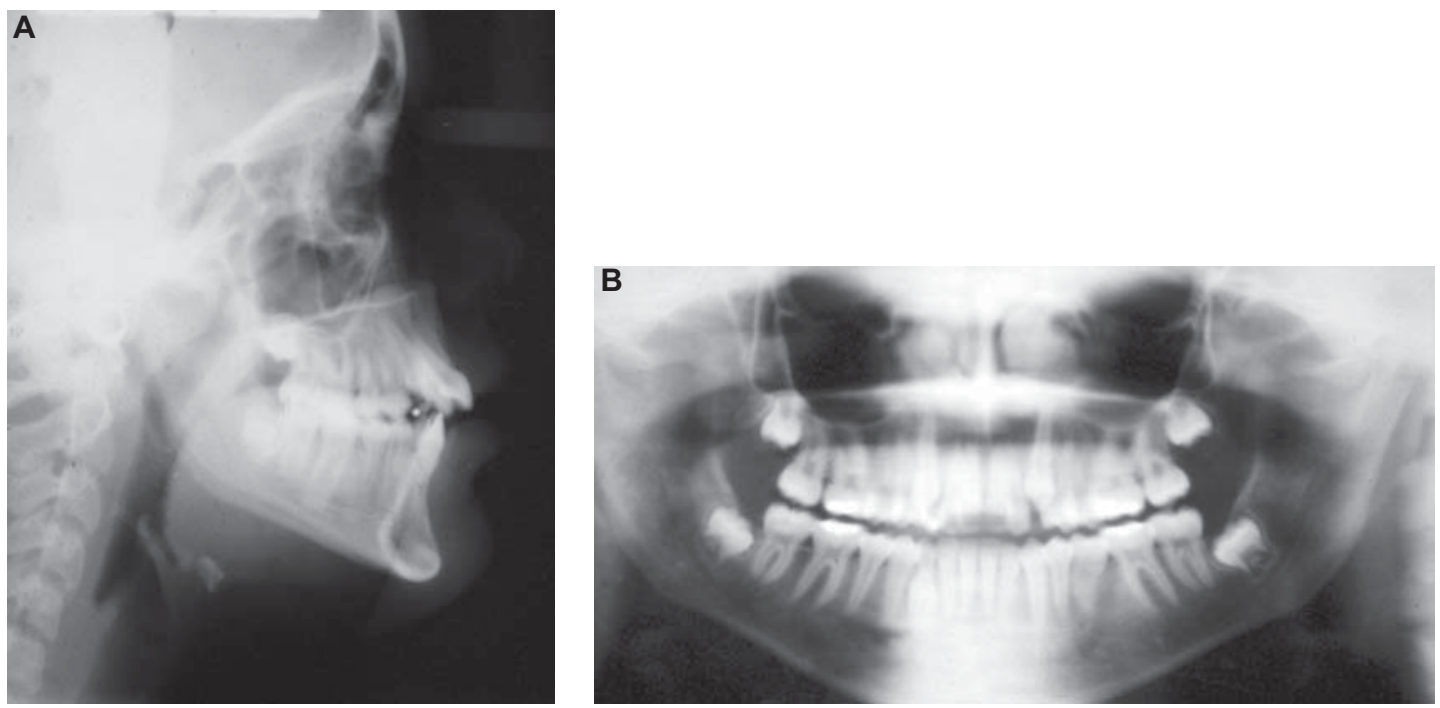

Figure 2- Initial lateral cephalograms (A) and panoramic radiograph (B) 
by the mentonian musculature. Additionally, an increased facial lower third and a convex profile were verified. Intraoral evaluation showed a Class II, division 1 malocclusion, and bilateral posterior crossbite (Figures 1 and 2, Table 1).

The treatment plan proposed was palatal expansion, performed by a modified Haas-type expander (Figure 3), aiming at increasing the maxillary transversal dimension to correct the bilateral posterior crossbite. Activation of the screw was initiated immediately after appliance insertion with a complete turn. After that (Figure 3 ), the patient was instructed to keep the activation with $2 / 4$ turns in the morning and 2/4

Table 1- Initial, final, $1^{\text {st }}$, and $2^{\text {nd }}$ follow-up cephalometric measures

\begin{tabular}{|c|c|c|c|c|c|}
\hline $\begin{array}{l}\text { CEPHALOMETRIC } \\
\text { VARIABLES }\end{array}$ & PATTERN & $\begin{array}{c}\text { Initial } \\
\text { (12.83 years) }\end{array}$ & $\begin{array}{c}\text { Final } \\
\text { (14.08 years) }\end{array}$ & $\begin{array}{l}1^{\text {st }} \text { Follow-up } \\
\text { (21.41 years) }\end{array}$ & $\begin{array}{l}2^{\text {nd }} \text { Follow-up } \\
(29.16 \text { years) }\end{array}$ \\
\hline $\mathrm{NAP}\left({ }^{\circ}\right)$ & 0.0 & 11.0 & 6.5 & 5.5 & 7.5 \\
\hline $\mathrm{SNA}\left({ }^{\circ}\right)$ & 82.0 & 83.0 & 82.0 & 82.0 & 82.0 \\
\hline $\operatorname{SNB}\left({ }^{\circ}\right)$ & 80.0 & 76.0 & 77.0 & 78.0 & 78.5 \\
\hline $\mathrm{ANB}\left({ }^{\circ}\right)$ & 2.0 & 7.0 & 5.0 & 4.0 & 3.5 \\
\hline $\mathrm{FMA}\left({ }^{\circ}\right)$ & 25.0 & 37.0 & 35.0 & 32.0 & 33.0 \\
\hline SN.GoGn( $\left(^{\circ}\right)$ & 32.0 & 42.0 & 42.0 & 40.0 & 40.0 \\
\hline $\operatorname{SN} . G n\left({ }^{\circ}\right)$ & 67.0 & 74.0 & 73.0 & 71,5 & 72.0 \\
\hline SN.Ocl( $\left.{ }^{\circ}\right)$ & 14.0 & 19.5 & 14.5 & 14.0 & 13.0 \\
\hline 1.NA $\left({ }^{\circ}\right)$ & 22.0 & 31.0 & 27.0 & 27.0 & 27.0 \\
\hline 1-NA(mm) & 4.0 & 5.5 & 5.5 & 5.5 & 5.0 \\
\hline 1.NB $\left({ }^{\circ}\right)$ & 25.0 & 15.5 & 23.5 & 22.0 & 24.0 \\
\hline 1-NB(mm) & 4.0 & 6.0 & 8.5 & 8.0 & 8.5 \\
\hline $\operatorname{IMPA}\left({ }^{\circ}\right)$ & 87.0 & 73.0 & 82.5 & 82.5 & 84.0 \\
\hline Co-A $(\mathrm{mm})$ & - & 94.0 & 94.5 & 96.0 & 97.0 \\
\hline Co-Gn(mm) & - & 124.0 & 128.5 & 134.0 & 132.0 \\
\hline $\operatorname{NLA}\left({ }^{\circ}\right)$ & 110.0 & 118.0 & 114.0 & 117.0 & 115.0 \\
\hline
\end{tabular}
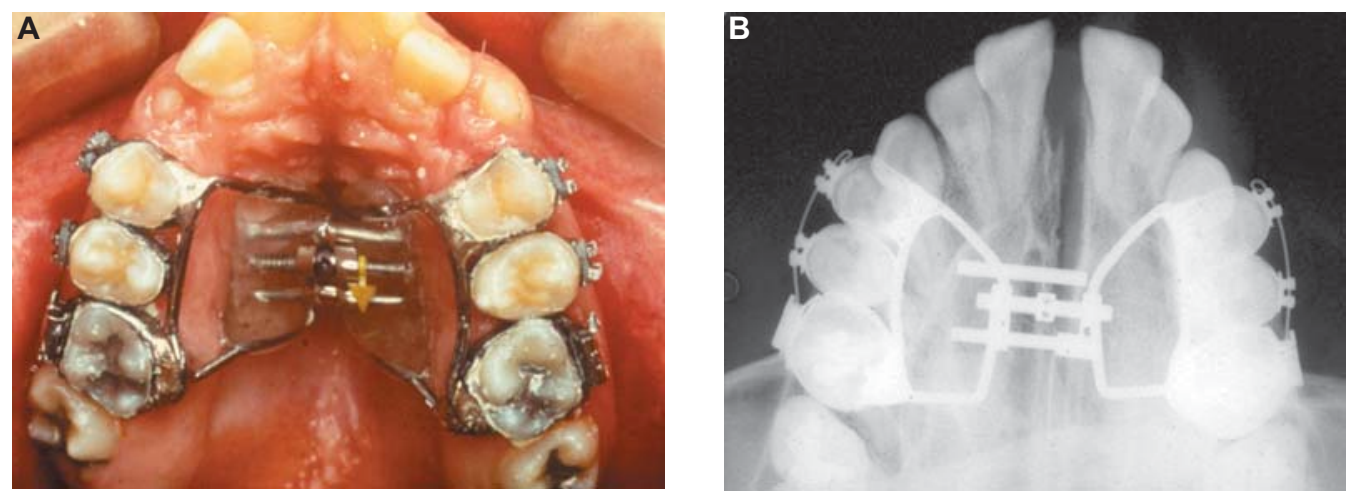

Figure 3- Intraoral aspects. Occlusal view showing the Haas-type expansion appliance installed (A) and the radiographic aspect (B)

turns in the afternoon, during eight days. The expander was passively maintained for a period of three months, followed by a removable retainer, which was used for another six months. At that time, a comprehensive orthodontic treatment was initiated in order to improve the results obtained after expansion (Figure 4). The whole treatment, including maxillary expansion and the comprehensive phase, lasted about 1 year and
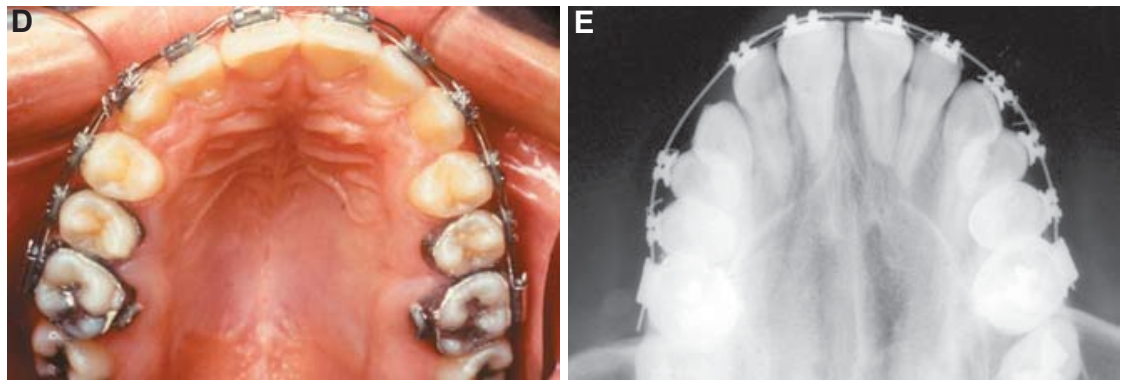

Figure 4- Intraoral (A-D) and radiographic (E) aspects of the fixed appliance
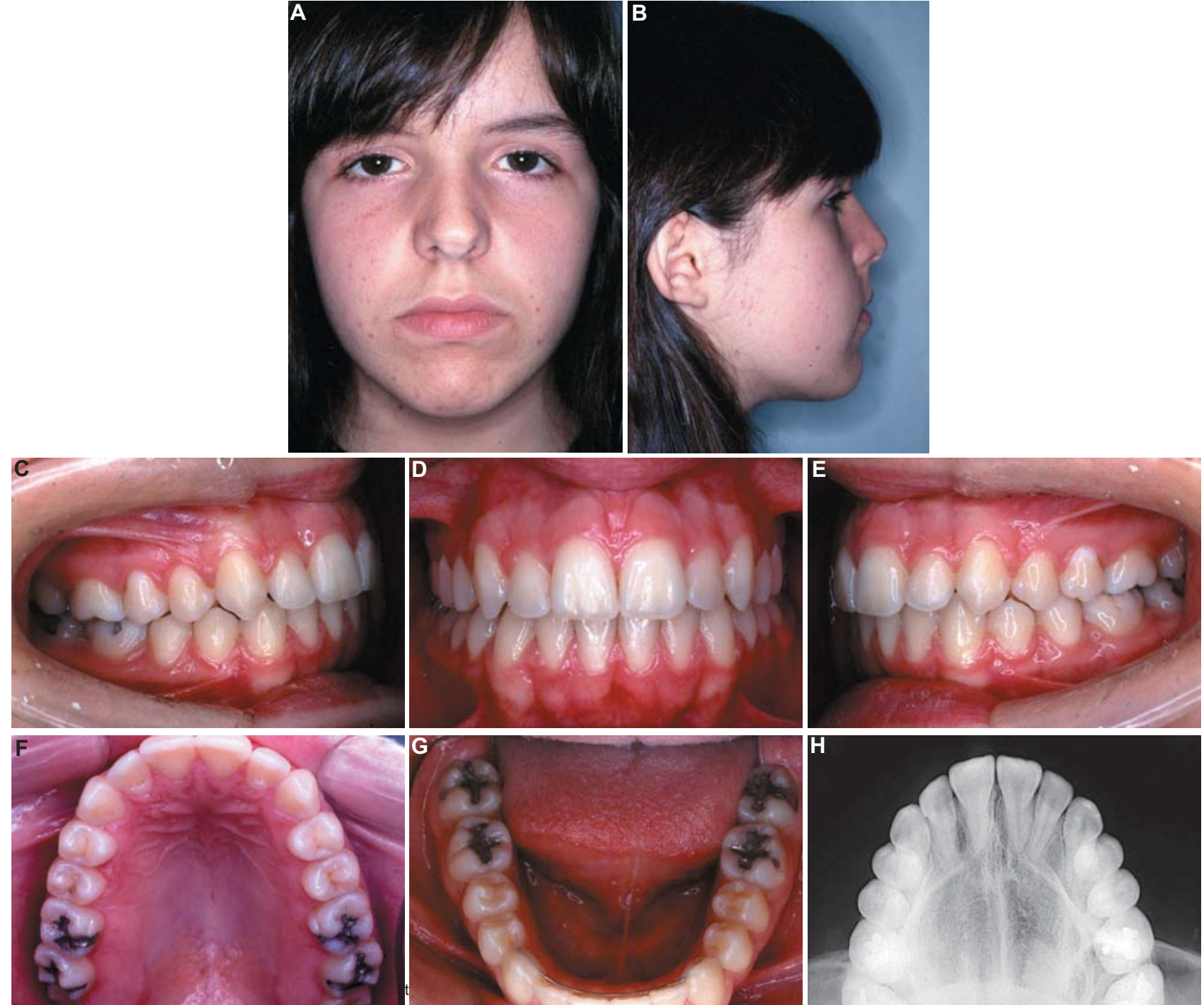

Figure 5- Extraoral (A and $B$ ) and intraoral $(C-G)$ photographs at the completion of treatment. Radiographic aspect $(\mathrm{H})$ (parents authorized the publication of these pictures) 

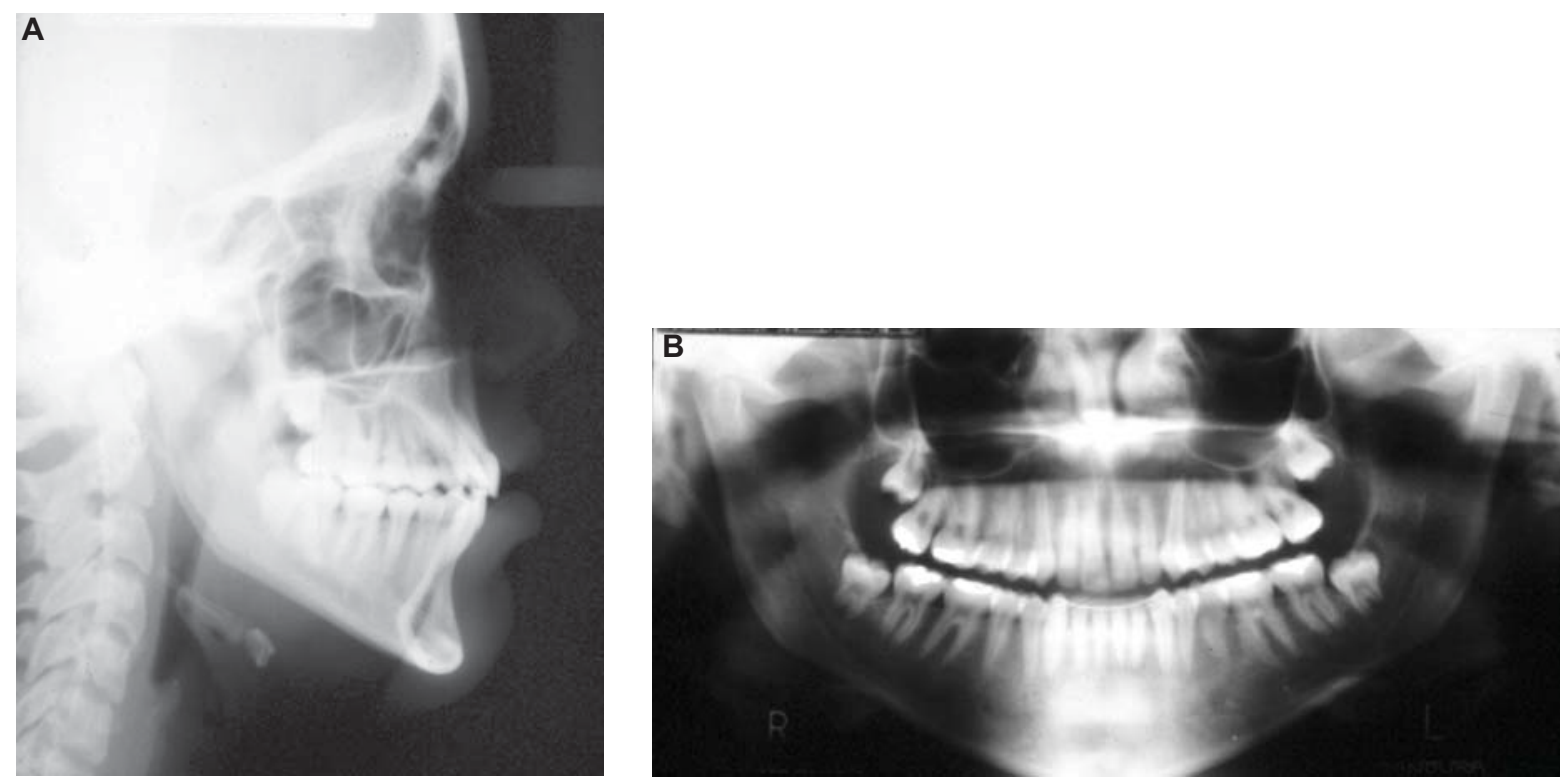

Figure 6- Final lateral cephalograms (A) and panoramic radiograph (B)
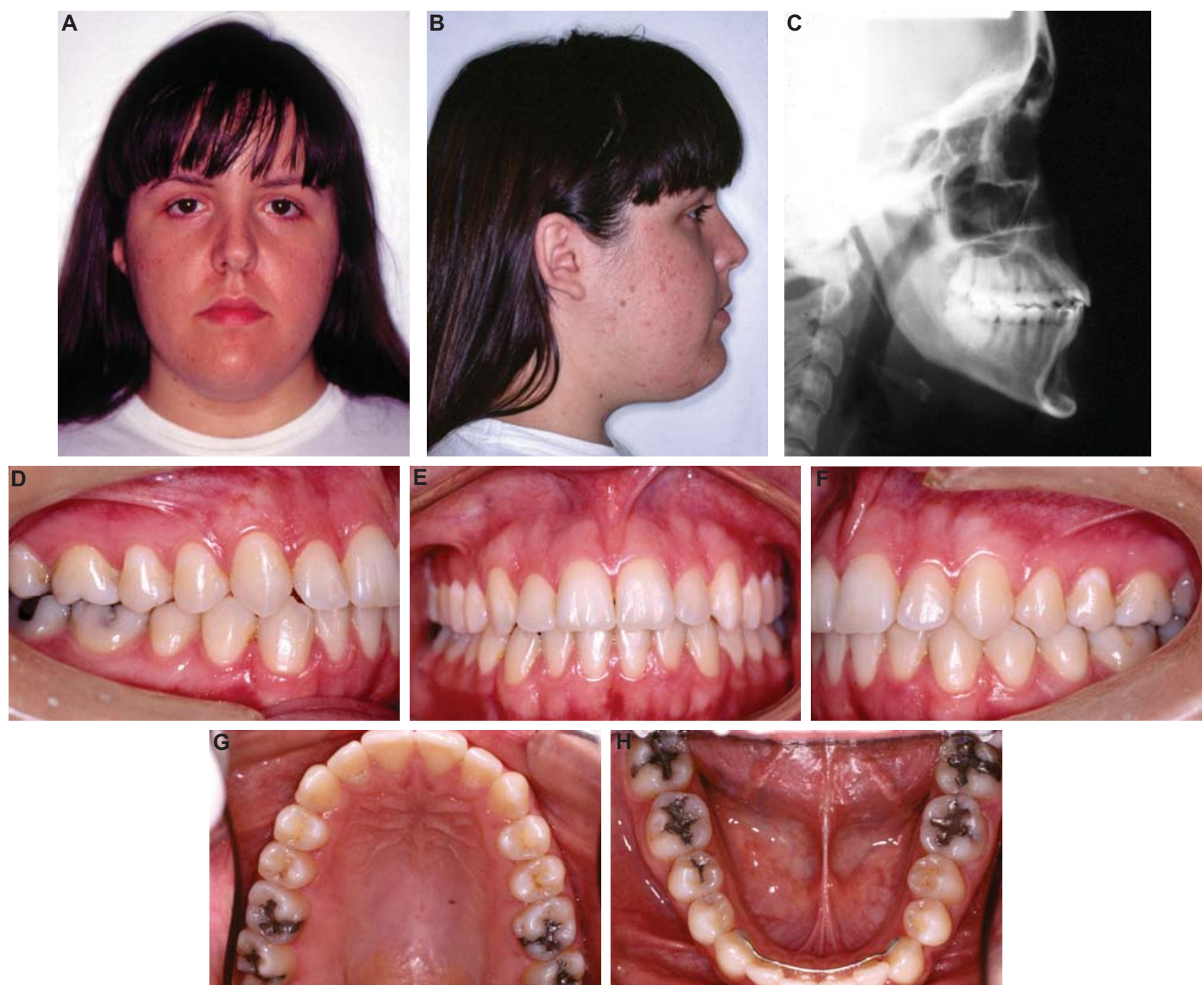

Figure 7- First follow-up appointment photographs. Extraoral (A and B) and intraoral (D-H). Lateral cephalograms (C) (parents authorized the publication of these pictures) 


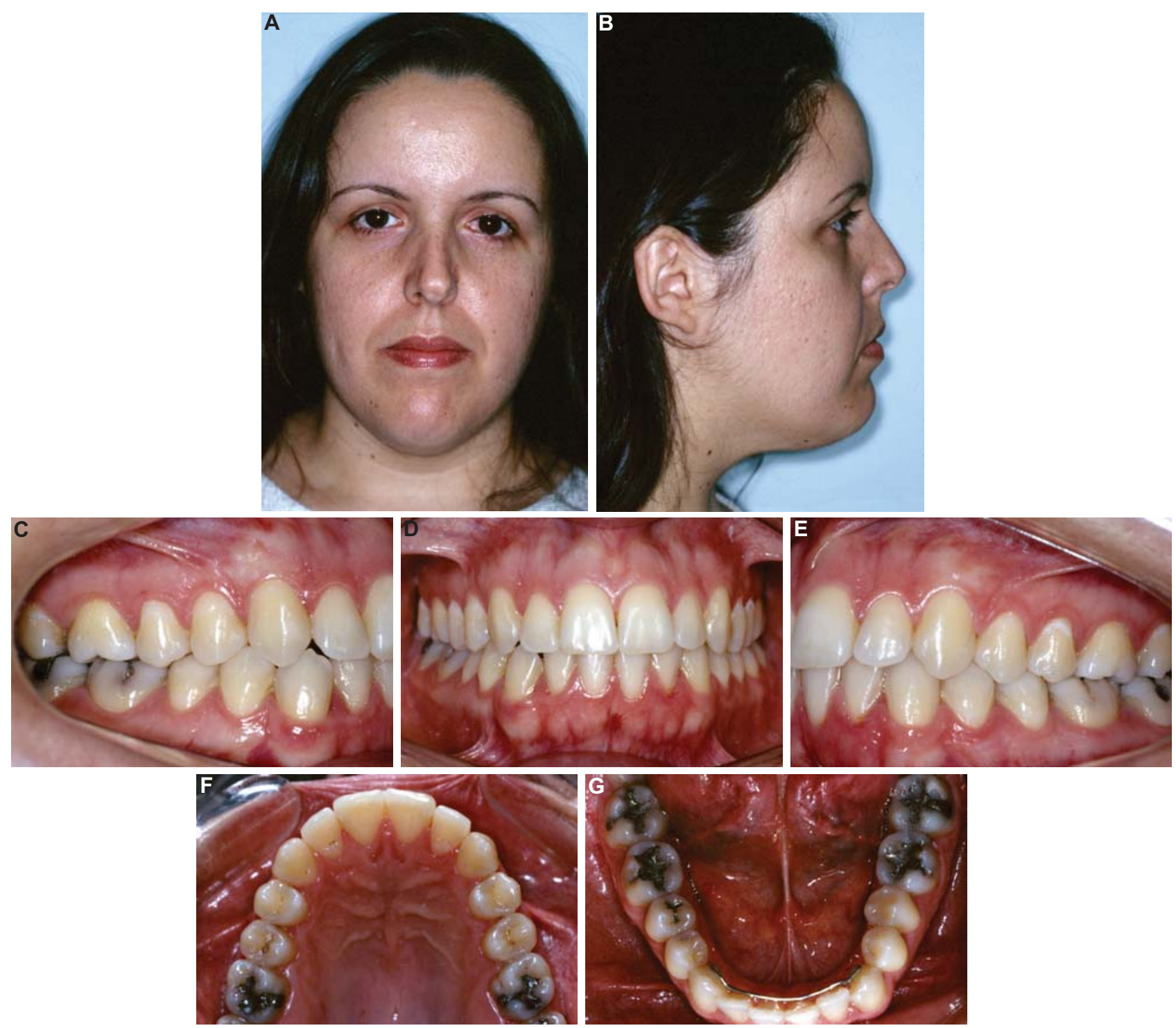

Figure 8- 14-year posttreatment extraoral (A and B) and intraoral (C-G) photographs (parents authorized the publication of these pictures)

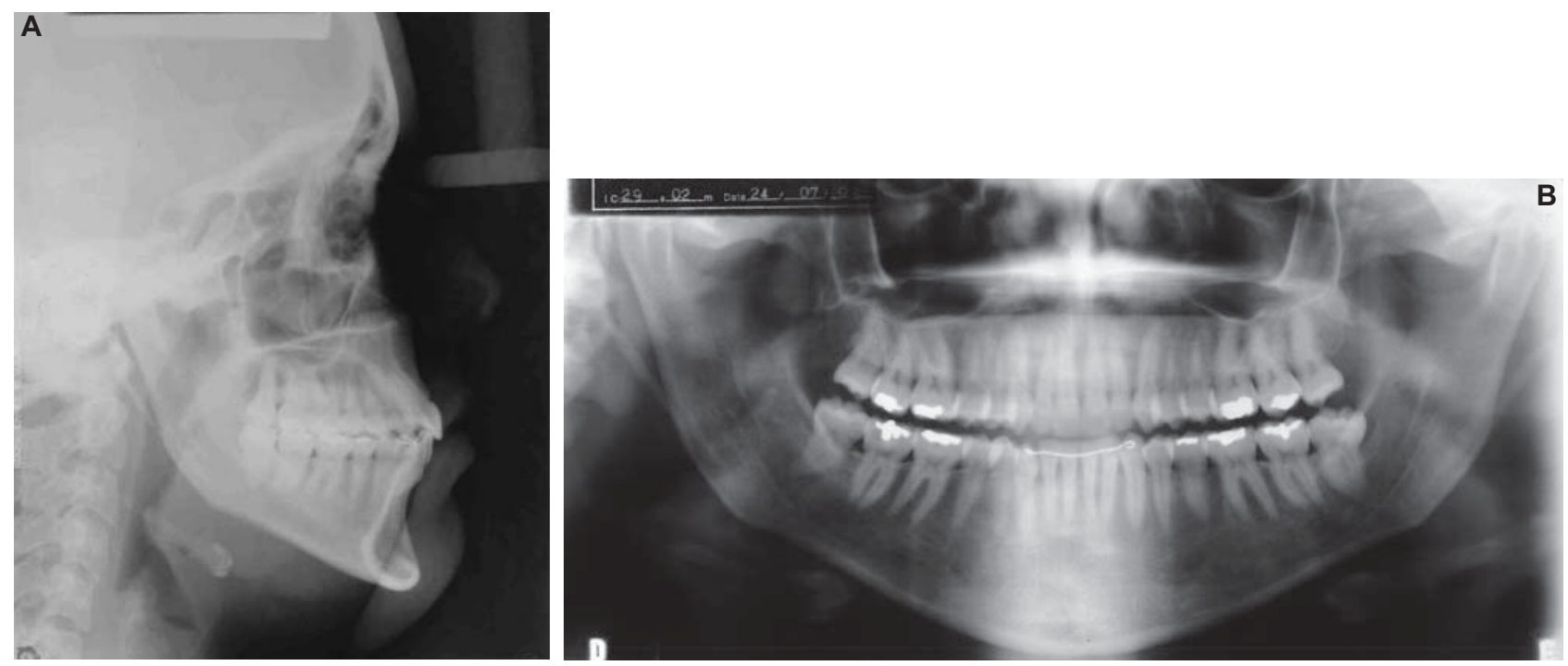

Figure 9- Lateral cephalograms (A) and panoramic radiograph (B) 14-year post-treatment 

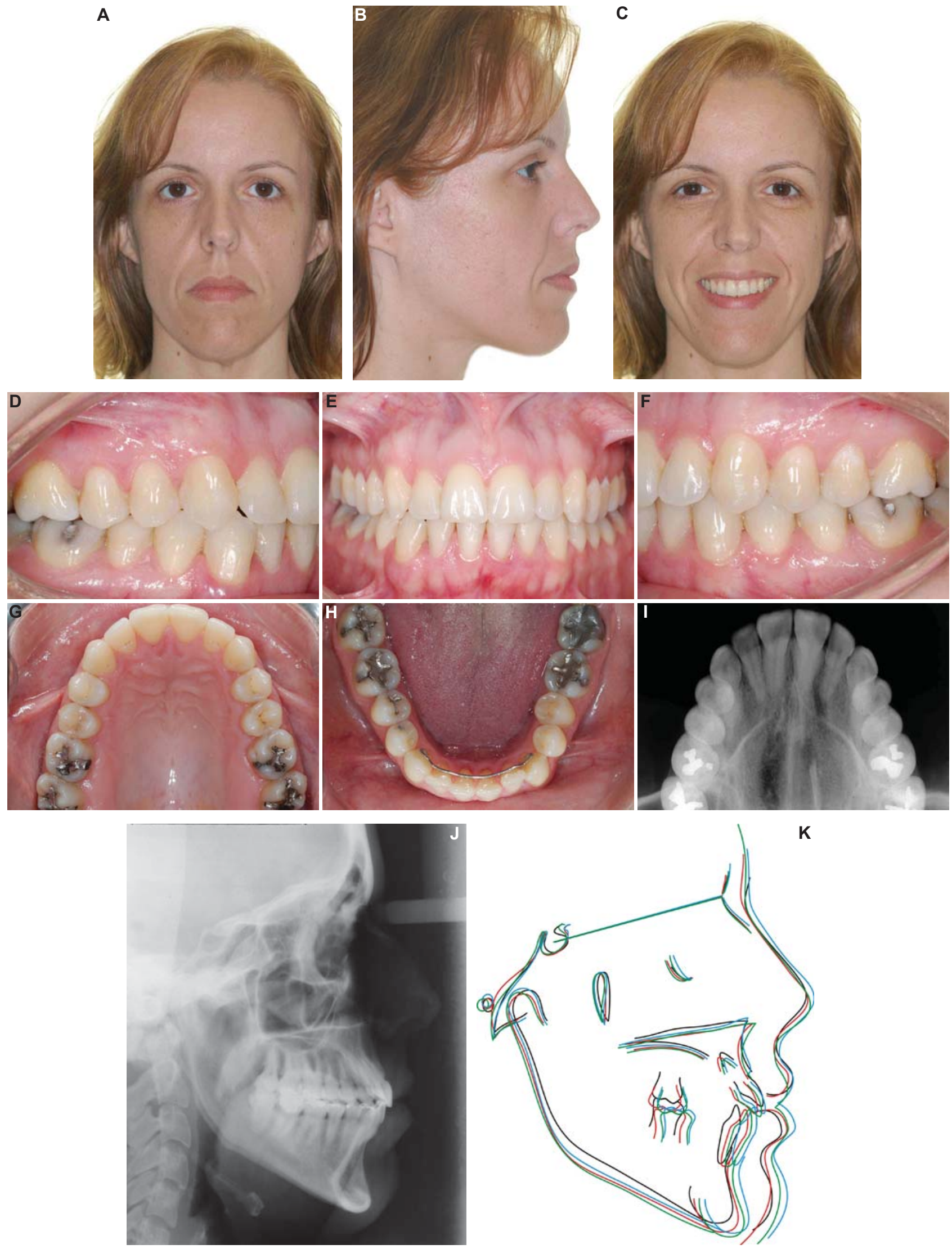

Figure 10- 22-year posttreatment extraoral ( $A$ and $C$ ) and intraoral (D-H) photographs. Lateral cephalograms (J), occlusal radiograph (I), total superpositions: initial (black), final (red), first follow-up (green), and second follow-up (blue) (K) (patient authorized the publication of these pictures) 


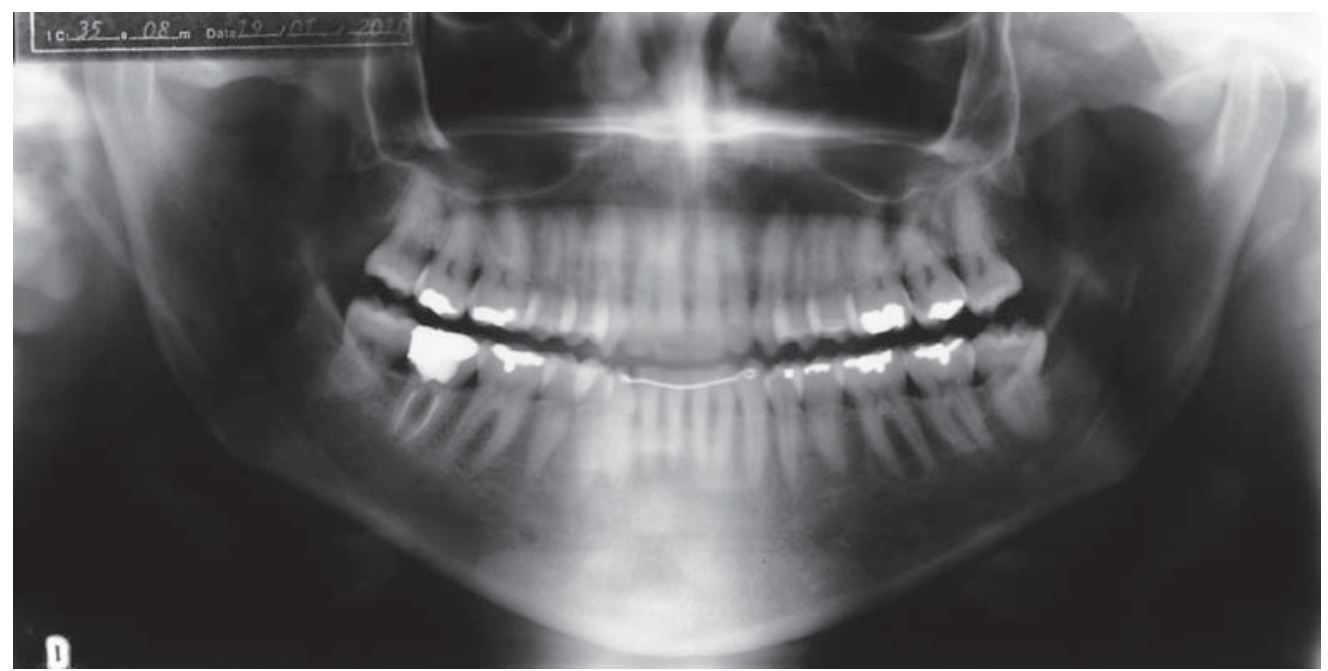

Figure 11- Panoramic radiograph

\section{DISCUSSION}

This case report challenges some studies ${ }^{12,14}$ in which this enlargement method of treatment was found to have a poor stability result. In the present case, the patient had bilateral skeletal posterior crossbite, and a modified Haas-type expansion appliance was indicated ${ }^{20}$. Early correction of posterior crossbite has been recommended in order to prevent an inadequate skeletal transversal growth.

Few studies have assessed the longitudinal stability of maxillary expansion ${ }^{3,13,17}$. The present case was treated, and followed-up in the long term (21 years), showing stability of the posterior crossbite correction. Additionally, the cephalometric variables obtained at the end of the treatment remained stable throughout the period following the study. These results are in agreement with what is expected for a female patient at this age, when the growth rate has declined significantly (Table 1 ).

Similar findings have been assessed by Bartzella, et al.3 (2007), who verified $79 \%$ of stability in cases evaluated in the long term. However, it is worth noting that their sample was composed of patients with unilateral posterior crossbite. Moreover, these authors observed that the stability was similar, regardless of the expansion performed (whether rapid or slow).

Studies have shown that $50 \%$ of posterior crossbite cases treated at primary dentition had to be retreated at mixed dentition ${ }^{12,14}$. Although these results indicated a high-incidence relapse of early treatment, other advantages have been attributed to this intervention. According to Harrison and Ashby $^{8}$ (2001), maxillary expansion in the primary dentition would decrease the risk of a posterior crossbite being perpetuated to a permanent dentition.
Rapid maxillary expansion promotes positive skeletal (orthopedic) and dental (orthodontic) effects, thus affording the correction of a maxillary transverse deficiency. Baccetti, et al. ${ }^{2}$ (2001) stated that a better prognosis is expected when applying this protocol at an early age. These authors verified that the maxillary skeletal width could be expanded without relapse in young patients. However, in adulthood they found greater skeletal rigidity, and consequently poor orthopedic results.

\section{CONCLUSION}

Based on this case report, a rapid maxillary expansion protocol carried out at mixed dentition was effective and stable 21 years post treatment.

\section{REFERENCES}

1- Arat ZM, Gökalp H, Atasever T, Türkkahraman H. 99mTechnetium-labeled methylene diphosphonate uptake in maxillary bone during and after rapid maxillary expansion. Angle Orthod. 2003;73(5):545-9.

2- Baccetti T, Franchi L, Cameron CG, McNamara JA Jr. Treatment timing for rapid maxillary expansion. Angle Orthod. $2001 ; 71(5): 343-50$.

3- Bartzela T, Jonas I. Long-term stability of unilateral posterior crossbite correction. Angle Orthod. 2007;77(2):237-43.

4- Bell RA, LeCompte EJ. The effects of maxillary expansion using a quad-helix appliance during the deciduous and mixed dentitions. Am J Orthod. 1981;79(2):152-61.

5 - Berlocher WC, Mueller $\mathrm{BH}$, Tinanoff $\mathrm{N}$. The effect of maxillary palatal expansion on the primary dental arch circumference. Pediatr Dent. 1980;2(1):27-30.

6- Celenza FV. The theory and clinical management of centric positions: II. Centric relation and centric relation occlusion. Int J Periodontics Restorative Dent. 1984;4(6):62-86.

7- Hannuksela A, Väänänen A. Predisposing factors for malocclusion in 7-year-old children with special reference to a topic diseases. Am J Orthod Dentofacial Orthop. 1987;92(4):299-303. 
8- Harrison JE, Ashby D. Orthodontic treatment for posterior crossbites. Cochrane Database Syst Rev. 2001;(1):CD000979. 9- Järvinen S. Need for preventive and interceptive intervention for malocclusion in 3--5-year-old Finnish children. Community Dent Oral Epidemiol. 1981;9(1):1-4.

10- Kantomaa T. Correction of unilateral crossbite in the deciduous dentition. Eur J Orthod. 1986;8(2):80-3.

11- Kisling $E$. Occlusal interferences in the primary dentition. ASDC J Dent Child. 1981;48(3):181-91.

12- Kurol J, Berglund L. Longitudinal study and cost-benefit analysis of the effect of early treatment of posterior cross-bites in the primary dentition. Eur J Orthod. 1992;14(3):173-9.

13- Lagravere MO, Major PW, Flores-Mir C. Long-term dental arch changes after rapid maxillary expansion treatment: a systematic review. Angle Orthod. 2005;75(2):155-61.

14- Lindner A. Longitudinal study on the effect of early interceptive treatment in 4-year-old children with unilateral crossbite. Scand J Dent Res. 1989;97(5):432-8.

15- Myers DR, Barenie JT, Bell RA, Williamson EH. Condylar position in children with functional posterior crossbites: before and after crossbite correction. Pediatr Dent. 1980;2(3):190-4.
16- O'Grady PW, McNamara JA Jr, Baccetti T, Franchi L. A longterm evaluation of the mandibular Schwarz appliance and the acrylic splint expander in early mixed dentition patients. Am J Orthod Dentofacial Orthop. 2006;130(2):202-13.

17- Sabri R. Treatment of a severe arch-length deficiency with anteroposterior and transverse expansion: long-term stability. Am J Orthod Dentofacial Orthop. 2010;137(3):401-11.

18- Silva Filho OG, Boas MCV, Capelozza Filho L. Rapid maxillary expansion in the primary and mixed dentitions: a cephalometric evaluation. Am J Orthod Dentofacial Orthop. $1991 ; 100(2): 171-9$.

19- Silva Filho OG, Montes LAP, Torelly LF. Rapid maxillary expansion in the dentition evaluated through posteroanterior cephalometric analysis. Am J Orthod Dentofacial Orthop. $1995 ; 107(3): 268-75$

20- Silva Filho OG, Valladares Neto J, Rodrigues de Almeida R. Early correction of posterior crossbite: biomechanical characteristics of the appliances. J Pedod. 1989;13(3):195-221. 